\title{
SUSPENSIÓN DE LA EJECUCIÓN DE UN TÍTULO EJECUTIVO EUROPEO TRAS LA ADMISIÓN A TRÁMITE DE UN RECURSO DE APELACIÓN CONTRA LA SENTENCIA CERTIFICADA
}

\author{
STAY OF THE ENFORCEMENT PROCEEDINGS OF A \\ EUROPEAN ENFORCEMENT ORDER AFTER THE ADMISSION \\ OF AN APPEAL AGAINST THE CERTIFIED JUDGMENT
}

\author{
JAVIER PÉREZ FonT \\ Abogado. LLM (Distinction) in International Commercial and Maritime Law (Swansea \\ University). Doctorando en Derecho Internacional Privado (Universidad Pública de Navarra) \\ ORCID ID: 0000-0002-1554-5420
}

Recibido: 28.10.2020 / Aceptado: 10.11.2020

DOI: https://doi.org/10.20318/cdt.2021.6011

Resumen: Habiéndose certificado una sentencia condenatoria contra un demandado rebelde como Título Ejecutivo Europeo, se admite a trámite recurso de apelación que pone de relieve que las notificaciones practicadas durante el proceso instándole a participar en él eran nulas de pleno derecho. A la vista de esta circunstancia, el tribunal ejecutante opta por suspender el proceso de ejecución de la sentencia impugnada al amparo del artículo 23(c) del Reglamento 805/2004.

Palabras clave: Título Ejecutivo Europeo, ausencia de firmeza, impugnación de la sentencia certificada.

Abstract: Having a default judgment been certified as a European Enforcement Order, its subsequent appeal reveals that notices were not served properly to the respondent, being so null and void. Considering these circumstances, the enforcing court opts for staying the enforcement proceedings under article 23(c) Regulation 805/2004.

Keywords: European Enforcement Order, want of authority of a final decision, appeal against certified judgment.

Sumario: I. Hechos. II. La falta de firmeza de la sentencia como motivo para denegar la ejecución. III. Modificación de facto de los elementos del certificado como consecuencia de la admisión de una impugnación de la resolución certificada como motivo para denegar la ejecución. IV. Aplicación de un motivo de oposición previsto en el ordenamiento jurídico del Estado ejecutante. V. Conclusiones.

\section{Hechos}

1. Encontrándose en rebeldía el demandado, la sección para Turnhout de la Cámara de Comercio de Amberes ${ }^{1}$ dictó el 30 de Septiembre de 2015 sentencia condenatoria por el importe de 100.000 euros. Al amparo del Reglamento 805/2004², el 18 de Enero de 2018 el mismo tribunal certificó aquélla como Título Ejecutivo Europeo.

\footnotetext{
${ }^{1}$ Ondernemingsrechtbank Antwerpen - Afdeling Turnhout según se denominación oficial en neerlandés flamenco.

${ }^{2}$ Reglamento (CE) 805/2004 del Parlamento Europeo y del Consejo, de 21 de Abril de 2004, por el que se establece un Título Ejecutivo Europeo para créditos no impugnados DOUE L143, de 30 abril 2004, pp. 15-39.
} 
Al instarse en España la ejecución del Título Ejecutivo Europeo, el demandado planteó oposición por defectos procesales contra el despacho de ejecución ${ }^{3}$, que fue íntegramente desestimada el 5 de Junio de 2019 por el Juzgado de Primera Instancia de Sant Feliu de Guíxols

2. Planteado ya el recurso de apelación contra el auto de desistimiento a la oposición a la ejecución, el ejecutado/apelante facilitó a la Audiencia Provincial de Girona traducción jurada de una sentencia de 12 de Septiembre de 2019 de la Corte de Apelación de Amberes ${ }^{5}$ en la que, a pesar del tiempo transcurrido ${ }^{6}$, se admitía a trámite recurso de apelación contra la sentencia de la Cámara de Comercio al entender que, siendo nulas las notificaciones realizadas en su día al demandado, los plazos fijados para la interposición del recurso no habían comenzado a correr.

3. Considerando que como consecuencia de la admisión del recurso de apelación la sentencia condenatoria objeto del Título Ejecutivo Europeo había perdido su firmeza ${ }^{7}$ y que se habían modificado de facto datos esenciales del formulario de certificación ${ }^{8}$, ante la imposibilidad de modificar o revocar el Título Ejecutivo Europeo emitido, la Audiencia Provincial de Girona opta por aplicar el artículo 23(c) del Reglamento 805/2004 y suspender el procedimiento de ejecución en tanto en cuanto el Título Ejecutivo Europeo no sea revocado o sustituido por otro que se acomode a lo que decidan de manera definitiva las autoridades judiciales belgas 9 .

\section{La falta de firmeza de la sentencia certificada como motivo para denegar la ejecución}

4. En la propuesta del Consejo del Reglamento que viniera a establecer el Título Ejecutivo Europeo ${ }^{10}$ se disponía que únicamente sería certificada como Título Ejecutivo Europeo aquella resolución que, siendo ejecutoria en el Estado de origen, hubiera además adquirido autoridad de cosa juzgada ${ }^{11}$. En este sentido, la propuesta del Consejo defendía que debía entenderse que una resolución adquiría autoridad de cosa juzgada cuando no hubiera recurso ordinario contra la misma o, cuando habiéndolo, hubiera transcurrido el plazo previsto para su interposición ${ }^{12}$. A su vez, la propuesta definía el recurso ordinario como aquél que pudiera dar lugar a la "anulación o a la modificación de la resolución objeto del procedimiento de certificación como Título Ejecutivo Europeo, cuya interposición esté sujeta, en el Estado miembro de origen, a un período fijado por ley y que se inicie en virtud de esa misma resolución"13.

5. Recibida la propuesta del Consejo, el Comité Económico y Social recomendó introducir algunas modificaciones en su articulado entre las cuales se hallaba una doble enmienda a la definición de recurso ordinario. Por un lado, considerando que la definición contenida en la propuesta del Consejo ofrecía muy poca seguridad jurídica sobre el momento de inicio del período de interposición del recurso ${ }^{14}$, siguiendo la

\footnotetext{
${ }^{3}$ Artículo 559 Ley 1/2000, de 7 de Enero, de Enjuiciamiento Civil.

${ }^{4}$ Auto Juzgado de Primera Instancia e Instrucción Número 1 de Sant Feliu de Guíxols de 5 de Junio de 2019.

${ }^{5}$ Hof van Beroep Antwerpen, según se denominación oficial en neerlandés flamenco.

${ }^{6}$ De acuerdo con el artículo 1051(1) del Code Judicaire o Gerechtelijk wetboek, el plazo de interposición del recurso de apelación en el derecho belga es de un 1 mes a contar desde la notificación de la sentencia. Por otro lado, con carácter general, el artículo 792 dispone que, bajo pena de nulidad, en el plazo de 8 días desde su adopción, la sentencia habrá de notificarse por el Secretario Judicial a cada una de las partes o a sus abogados indicando los medios de impugnación disponibles frente la sentencia notificada, el plazo para su interporsición y la dirección del órgano judicial competente para conocer de ellos.

${ }^{7}$ Auto Audiencia Provincial de Girona AAP GI 522/2020, de 10 de Junio, Fundamento de Derecho $5^{\circ}$.

${ }^{8}$ ibidem, Fundamentos de Derecho $5^{\circ}$ y $6^{\circ}$.

${ }^{9}$ ibidem, Fundamentos de Derecho $6^{\circ}$ y $8^{\circ}$.

${ }^{10}$ Propuesta de Reglamento del Consejo por el que se establece un Título Ejecutivo Europeo para créditos no impugnados, DOCE C203E, de 27 de Agosto de 2002, pp,86-107.

${ }^{11}$ ibidem, artículo 5(a).

${ }^{12}$ ibidem, Artículo 3(5).

${ }^{13}$ ibidem, Artículo 3(6).

${ }^{14}$ Dictamen del Comité Económico y Social Europeo sobre la "Propuesta de Reglamento del Consejo por el que se establece un Título Ejecutivo Europeo para crédito no impugnados", DOUE C85, de 8 de Abril de 2003, pp. 1-7, párrafo 4.1.
} 
definición dada por el Tribunal de Justicia de la Unión Europea en el caso Industrial Diamond ${ }^{15}$, el Comité consideraba que el Reglamento debía establecer que el período de interposición del recurso fijado por la ley debía iniciarse "como consecuencia de la propia resolución cuya ejecución se persigue o como consecuencia de una notificación de la resolución" ${ }^{16}$. Por otro lado, con el objetivo de determinar de manera clara y precisa qué recursos respondían exactamente a la definición reglamentaria, el Comité recomendaba una matización suplementaria que precisara que, a efecto del Reglamento, sería ordinario el recurso propio del curso normal de un procedimiento que, constituyendo un desarrollo del procedimiento, debiera ser lógicamente tenido en cuenta por todas las partes ${ }^{17}$.

6. Considerando que el Reglamento sobre el Título Ejecutivo Europeo debía ir más allá del régimen establecido en el Reglamento Bruselas $\mathrm{I}^{18}$ - el cual, al igual que hacia su predecesor ${ }^{19} \mathrm{y}$ hace su sucesor $^{20}$, no exigía a la resolución autoridad de cosa juzgada, sino ser ejecutiva en el Estado de origen ${ }^{21}$ - y que los conceptos de "sentencia firme", "recurso ordinario" o "cosa juzgada" tenían difícil encaje en los ordenamientos common law $w^{22}$, el legislador comunitario finalmente optó por prescindir del requisito de la autoridad de cosa juzgada - y, por tanto, de las definiciones de cosa juzgada y recurso ordinario que llevaba aparejada - y vincular la aplicabilidad del Reglamento sobre el Título Ejecutivo Europeo a la ejecutabilidad de la resolución certificada conforme al ordenamiento jurídico del Estado dónde se hubiera dictado ${ }^{23}$.

7. De lo dicho hasta ahora se desprende que, no siendo la firmeza de la resolución un requisito necesario para ser certificada como Título Ejecutivo Europeo, no se puede compartir la afirmación de la Audiencia Provincial de Girona de que, como consecuencia de la pérdida de firmeza generada por la admisión a trámite de un recurso de apelación contra la sentencia de la Cámara de Comercio de Amberes, decaiga "el efecto esencial del [Título Ejecutivo Europeo] al no ser firme la sentencia objeto de ejecución" (énfasis añadido) ${ }^{24}$.

15 Sentencia del Tribunal de Justicia de la Unión Europea, de 22 de Noviembre de 1977, Industrial Diamond, C-43/77, párrafos 37 y 38 .

${ }^{16}$ Dictamen del Comité Económico... op. cit., párrafo 4.1.

${ }^{17}$ ibidem, párrafo 4.1.1.

${ }^{18}$ Esta pretensión se manifiesta de manera expresa en el considerando número 9 del Reglamento 805/2004 al afirmar que el procedimiento en él contenido "debe ofrecer importantes ventajas con respecto al procedimiento de exequátur contenido en el [Reglamento Bruselas I] (...)”. Ver: F.J. Garcimartín Alférez, El Título Ejecutivo Europeo, Aranzadi, Navarra, 2006, párrafo 50.

${ }^{19}$ Artículo 31 del Convenio de Bruselas de 1968 relativo a la competencia judicial y a la ejecución de resoluciones judiciales en materia civil y mercantil.

${ }^{20}$ Artículo 39 del Reglamento 1215/2012, de 12 de diciembre de 2012, relativo a la competencia judicial, el reconocimiento y la ejecución de resoluciones judiciales en materia civil y mercantil.

${ }^{21}$ Artículo 38(1) del Reglamento 44/2001, de 22 de diciembre de 2000, relativo a la competencia judicial, el reconocimiento y la ejecución de resoluciones judiciales en materia civil y mercantil.

${ }^{22}$ Problemas ya expuestos en 1979 por Schlosser en su famoso informe sobre la incorporación de Dinamarca, Reino Unido e Irlanda al Convenio de Bruselas de 1968. Ver: Report on the association of the Kingdom of Denmark, Ireland and the United Kingdom of Great Britain and Northern Ireland to the Convention on jurisdiction and enforcement of judgment in civil and commercial matters and to the protocol on its interpretation by the Court of Justice, DOCE C59, de 5 de Marzo de 1979, pp. 71-151, párrafos 195-204.

${ }^{23}$ Artículo 6(1)(a) Reglamento 805/2004. Como es sabido, junto a la ejecutabilidad en el Estado de origen, el artículo 6(1) condiciona la emisión del certificado al cumplimiento acumulativo de 3 requisitos, a saber: (1) el tribunal de origen debe haber respetado ciertas normas de competencia internacional; (2) se deben haber cumplido las normas mínimas de procedimiento fijadas en el Reglamento; y (3), en el caso de que el deudor sea un consumidor, éste debe tener su domicilio en el Estado de origen. Ver: A.L. Calvo Caravaca, J. Carrascosa González, Derecho Internacional Privado: Volumen I, Comares, Granada, 2018, p. 742; J. RodrígUEZ Rodrigo, "Procedimiento contradictorio en el marco de documentos públicos que reconocen créditos no impugnados. Comentario a la sentencia del Tribunal de Justicia de la Unión Europea, de 9 de Marzo de 2017, Ibrica Zulfikarpasic, C-484/15", Cuadernos de Derecho Transnacional (Octubre 2017), Volumen 9, Número 2, pp. 685-691, p. 687; C. SenÉs Motilla, "El Título Ejecutivo Europea para crédito no impugnados" en Derecho Procesal Civil Europeo: Volumen III, Aranzadi, Navarra, 2011, p. 95; M.A. Rodríguez VÁzquez, El Título Ejecutivo Europeo, Colex, Madrid, 2005, p. 60; F. GASCóN InCHAusti, El Título Ejecutivo Europeo para Créditos No Impugnados, Aranzadi, Navarra, 2005, pp. 107-110; F.J. GARCIMARTíN Alférez, El Título Ejecutivo... op. cit., párrafo 47

${ }^{24}$ Auto Audiencia Provincial de Girona AAP GI 522/2020, de 10 de Junio, Fundamento de Derecho $5^{\circ}$ 


\section{Modificación de facto de los elementos del certificado como consecuencia de la admisión de una impugnación de la resolución certificada como motivo para denegar la ejecución:}

8. La Audiencia Provincial de Girona afirma que la admisión a trámite del recurso de apelación produce de facto una modificación esencial de los epígrafes 6, 7, 12(1), 13(3) y 13(4) del formulario de certificación que, junto a la pérdida de firmeza de la sentencia certificada, abundan en que no se cumplen los requisitos legales que llevan aparejada la ejecución que exige el artículo 559(1)(1)(3 $\left.{ }^{\circ}\right)$ LEC $^{25}$.

9. Resulta incuestionable que las consideraciones de la Corte de Apelación de Amberes en su admisión del recurso contra la sentencia objeto de certificación ponen de relieve que las notificaciones practicadas al entonces demandado y posteriormente condenado no brindaron a éste la debida oportunidad de defenderse. Esto conlleva que, no habiéndose cumplido con las normas mínimas del Capítulo III del Reglamento 805/2004, la Cámara de Comercio de Amberes probablemente no debería haber certificado como título ejecutivo su sentencia condenatoria.

Lo dicho no obsta a que la postura adoptada por la Audiencia Provincial de Girona no pueda ser tildada como exorbitante al amparo del Reglamento. Éste se fundamenta en una distribución nítida de funciones entre el tribunal certificante y el ejecutante, no siendo propio de este último revisar la corrección ni de la sentencia certificada, ni de los datos consignados en el propio certificado ${ }^{26}$. Siendo así, parece lógico concluir que el tribunal ejecutante tampoco puede entrar a valorar el impacto que la admisión a trámite de un recurso tiene sobre la información contenida en los epígrafes del formulario de certificación, especialmente cuando dichos epígrafes registran una realidad fáctica y jurídica previa a la existencia misma del recurso, y cuando dicho impacto va a depender en gran medida de un ordenamiento jurídico que le es ajeno, el del Estado de origen de la resolución certificada.

10. Por tanto, en la medida en que el tribunal ejecutante no puede revisar o corregir el certifi$\mathrm{cado}^{27}$, la Audiencia Provincial de Girona se excede al valorar el impacto que la admisión a trámite del recurso de apelación tiene sobre la información consignada en ciertos epígrafes del certificado expedido por las autoridades belgas. Habrán de ser éstas las que, a instancia de parte, deban realizar esa valoración y expedir en su caso el correspondiente certificado de falta o limitación de ejecutividad ${ }^{28}$.

\section{Aplicación de un motivo de oposición previsto en el ordenamiento jurídico del Estado ejecu- tante}

11. Como es bien sabido, excepción hecha de algunos aspectos puntuales, el Reglamento 805/2004 no regula el proceso de ejecución de la resolución certificada como Título Ejecutivo Europeo, optando en su lugar por un reenvío al ordenamiento jurídico del Estado miembro de ejecución ${ }^{29}$.

\footnotetext{
${ }^{25}$ ibidem.

${ }^{26}$ Artículo 21(2) Reglamento 805/2004. En este sentido, el considerando 18 del Reglamento expresamente dispone que el principio de confianza recíproca en la administración de justicia de los Estados miembros justifica que, una vez certificada una resolución como Título Ejecutivo Europeo, los órganos jurisdiccionales que conozcan de su ejecución no "procedan a revisar si se han cumplido las normas mínimas procesales".

${ }^{27}$ Como afirma SENÉs, la prohibición de revisión impuesta por el artículo 21(2) Reglamento es de carácter absoluto y “comprende tanto el objeto del proceso sustanciado ante el tribunal de origen (la pretensión del acreedor) como la atribución de fuerza ejecutiva supranacional (fuerza ejecutiva, carácter no impugnado del crédito y [cumplimiento de las] normas mínimas) y la regularidad formal del certificado" [C. Senés Motilla, "El Título Ejecutivo...”, op. cit., página 105]. Ver: P. BlanCo-MoraleS Limones, "El Título Ejecutivo Europeo", Anales de la Academia Matritense del Notariado, Tomo 45-46 (Cursos 2004-2005 y 2005-2006), pp. 243-256, p. 245; F. Gascón Inchausti, El Título Ejecutivo Europeo... op. cit., p. 185.

${ }_{28}^{8}$ Artículo 10 del Reglamento 805/2004. Ver: F.J. Garcimartín AlfÉrez, "El Título Ejecutivo Europeo", Anales de la Academia Matritense del Notariado, Tomo 47 (Curso 2006-2007), pp. 133-162, pp. 155-156; F. Gascón Inchausti, El Título Ejecutivo Europeo... op. cit., pp. 165-173.

${ }^{29}$ Los aspectos procesales de la ejecución regulados por el Reglamento son meramente cuatro, a saber: (1) la documentación que el ejecutante ha de facilitar [artículo 20(2)]; (2) la prohibición de la cautio iudicatum solvi [artículo 20(3)]; (3) los
} 
Considerando que el Reglamento sí prevé motivos de denegación de la ejecución en los artícu$\operatorname{los} 21$ y $22^{30}$, la interpretación del alcance de la remisión al ordenamiento jurídico del Estado ejecutante en relación con los motivos de denegación de la ejecución ha dado lugar a dos posturas doctrinales: mientras unos defienden que, abordándose específicamente por el Reglamento, la remisión no tiene cabida en esta materia, pudiéndose por tanto únicamente denegar la ejecución del Título Ejecutivo Europeo por los motivos específicamente previstos en el Reglamento ${ }^{31}$; otros defienden que, en la medida en que la ejecución ha de realizarse en las mismas condiciones que las resoluciones dictadas en el Estado ejecutante, se podrán aplicar aquellos motivos de denegación previstos en el ordenamiento jurídico del Estado ejecutante que no entren en contradicción con el Reglamento ${ }^{32}$.

12. Como se ha referido anteriormente, la Audiencia Provincial de Girona concluye que, como consecuencia de la perdida de firmeza de la resolución certificada y de una supuesta modificación de facto de los datos esenciales consignados en ciertos epígrafes del certificado, cabe apreciar el motivo de oposición previsto en el artículo 559 (1) (1) (3º LEC al considerar que el Título Ejecutivo Europeo no reúne los requisitos legales que llevan aparejada su ejecución ${ }^{33}$.

Examinada esta postura de la Audiencia Provincial de Girona desde el punto de vista doctrinal que circunscribe la denegación de la ejecución a los motivos previstos en el Reglamento, la aplicación del artículo 559 LEC es obviamente errónea al no tratarse de un motivo contemplado en los artículos 21 o 22 del Reglamento.

Por otro lado, examinada la postura de la Audiencia Provincial de Girona bajo el prisma de una aplicación limitada de los motivos de denegación previstos en el ordenamiento jurídico del Estado ejecutante $^{34}$, en la medida en que el motivo de denegación aplicado por la Audiencia Provincial de Girona

motivos de denegación de la ejecución [artículos 21 y 22]; y (4) los supuestos en que se podrá suspender la ejecución. En lo restante se aplicará el derecho del Estado en que se pretende la ejecución. Ver: M.A. Rodríguez Vázquez, El Título Ejecutivo... op. cit., p.117; F.J. Garcimartín AlfÉrez, El Título Ejecutivo... op. cit., párrafo 121; F. Gascón Inchausti, El Título Ejecutivo Europeo... op. cit., pp. 175-176.

${ }^{30}$ Al no haber celebrado España antes de la entrada en vigor del Reglamento 44/2001 acuerdo alguno residenciable en el artículo 59 del Convenio de Bruselas de 1968, el motivo de denegación previsto en el artículo 22 Reglamento 805/2004 carece de trascendencia en relación con la ejecución de títulos ejecutivos europeos en España. Ver: F.J. GarcimarTín Alférez, El Título Ejecutivo... op. cit., párrafo 127; C. SenÉs Motilla, “El Título Ejecutivo...”, op. cit., página 104; F. Gascón InCHAUSTI, El Título Ejecutivo Europeo... op. cit. p. 191.

${ }^{31}$ J-P. Béraudo, "Le Règlement (CE) Du Conseil Du 22 Décembre 2000 Concernant La Compétence Judiciaire, La Reconnaissance et l'exécution Des Décisions En Matière Civile et Commerciale", Journal du Droit International, 2011, pp. 1033-1084.

${ }^{32}$ F.J. Garcimartín Alférez, "El Título Ejecutivo...” op. cit., p. 159, C. Senés Motilla, "El Título Ejecutivo...” op. cit., pp. 101-107; M.A. Rodríguez VÁzquez, El Título Ejecutivo... op. cit., pp. 127-128; F. Gascón Inchausti, El Título Ejecutivo Europeo... op. cit. pp. 184-185.

${ }^{33}$ Auto Audiencia Provincial de Girona AAP GI 522/2020, de 10 de Junio, Fundamento de Derecho $5^{\circ}$.

${ }^{34} \mathrm{La}$ aplicabilidad de motivos previstos en el ordenamiento jurídico del Estado ejecutante siempre y cuando no contravengan lo previsto en el Reglamento parece ser la postura adoptada por los tribunales españoles. Por ejemplo, en el caso resuelto mediante el Auto de 29 de Julio de la Audiencia Provincial de Barcelona - AAP B 4357/2008 -, el ejecutado opuso sin éxito más de 8 motivos de oposición. De entre ellos, el ejecutado alegó haber realizado con carácter previo a la adopción del Título Ejecutivo Europeo un pago por una cantidad superior a la que pudiera reclamársele por el ejecutante. En este sentido, la Audiencia Provincial de Barcelona consideró que, en la medida en que implicaba una revisión del fondo del asunto, la excepción de pluspetición no podría ser opuesta ante el tribunal ejecutante. En cambio, la Audiencia sí consideró que podría alegarse la existencia de un pago, pero que para poder ser estimada debería acreditarse perfectamente la correlación entre el pago y la deuda que consta en el Título Ejecutivo Europeo, no siendo suficiente la mera posibilidad como alegaba el ejecutado. En el mismo sentido, la Audiencia Provincial de Almería en un Auto de 30 de Julio- AAP AL 357/2008 - consideró que cumpliendo con las condiciones necesarias de autenticidad y no pudiendo realizar una revisión sobre su validez formal, no se podía denegar la ejecución de un Título Ejecutivo Europeo al amparo del artículo 559(1)(1)(3 $3^{\circ}$ LEC por haberse aquél expedido en Español y no en Alemán, la lengua en que se había dictado la sentencia certificada. Por último, en el caso resuelto mediante el Auto de 26 de Septiembre de la Audiencia Provincial de Pontevedra - AAP PO 211/2011 -, el ejecutado alegaba la nulidad por vulneración del artículo 24 de la Constitución del despacho de ejecución de un Título Ejecutivo Europeo emitido en Francia. Considerando tanto que el Título Ejecutivo Europeo aparecía completo y conforme al formulario correspondiente, como que el tribunal ejecutante "no puede revisar la legalidad de las condiciones previstas en el Reglamento", la Audiencia Provincial de Pontevedra rechazó que la parte ejecutada pudiera alegar la nulidad radical del despacho de ejecución. Ver: E. SANJuAn y MuÑoz, "El Título Ejecutivo Europeo", Diario La Ley (2004), Vol. 4, pp. 1744-1758, pp. 1756-1757, F.J. Garcimartín AlfÉrez, El Título Ejecutivo... op. cit., párrafo 124; F. GASCón InCHAUSTI, El Título Ejecutivo Europeo... op. cit. pp. 184-191. 
implica una revisión tanto de la resolución certificada como del certificado mismo, su aplicación contravendría lo previsto en el artículo 21 del Reglamento y, por tanto, sería igualmente censurable.

13. En consecuencia, tanto por tratarse de un motivo no previsto en el Reglamento, como por implicar una revisión de la resolución certificada y del certificado prescrita por el Reglamento, la denegación de la ejecución con base en el artículo 559(1)(1)(3º LEC podría considerase incorrecta.

\section{Conclusión}

14. Planteado y admitido el recurso de apelación, a la luz del artículo 23 del Reglamento 805/2004, la Audiencia Provincial de Girona podía discrecionalmente elegir entre tres opciones: limitar el procedimiento de ejecución a la adopción de medidas cautelares ${ }^{35}$, subordinar la ejecución del título a la constitución de una garantía, o suspender el procedimiento de ejecución ${ }^{36}$.

Circunscribiéndose por el citado artículo 23 la aplicabilidad de la suspensión de ejecución a la concurrencia de circunstancias excepcionales, podría debatirse si las circunstancias presentes en el caso pueden ser consideradas como tales o $\mathrm{no}^{37}$. En mi opinión, en la medida en que el ejecutado no tuvo oportunidad real de defenderse durante el procedimiento del que trae causa la sentencia cuya ejecución se busca ante la Audiencia Provincial de Girona, la suspensión de la ejecución podría considerarse oportuna al constituir la alternativa de las previstas en el artículo 23 menos gravosa para una parte que ya de por si ha visto quebrantada su derecho de defensa.

15. No obstante, aun estando de acuerdo con la decisión material de la Audiencia Provincial, no se puede compartir la forma en que la alcanza o la motivación utilizada. Constatada la admisión del recurso de apelación por las autoridades judiciales de Amberes, la Audiencia Provincial debería haberse limitado a aplicar el artículo 23 del Reglamento y obviar las referencias a la pérdida de firmeza de la sentencia objeto de certificación - cuestión intrascendente a efectos de la aplicación del Reglamento - o a las consecuencias que dicho recurso tiene sobre la información consignada en el certificado - cuestión ésta ha de dilucidarse por la justicia belga llegado el momento oportuno -.

\footnotetext{
${ }^{35}$ En este sentido, las "medidas cautelares" deben entenderse en sentido impropio, refiriéndose así el Reglamento a las medidas de garantía o de aseguramiento del embargo, es decir, en el caso del ordenamiento jurídico español a las medidas previstas artículos 621 - 633 de la Ley de Enjuiciamiento Civil. Ver: F.J. Garcimartín Alférez, El Título Ejecutivo... op. cit., párrafo 133, C. SenÉs Motilla, “El Título Ejecutivo...” op. cit., p. 107; F. Gascón Inchausti, El Título Ejecutivo Europeo... op. cit. pp. 192-193.

${ }^{36}$ A la hora de decidir qué decisión adoptar, SANJUAN y MuÑoz considera que el tribunal ejecutante deberá tener en cuenta "las perspectivas de éxito de las medidas adoptadas por el deudor y la probabilidad de que se ocasione un perjuicio irreparable por una ejecución incondicional” [E. SANJUAN y MuÑoz, "El Título Ejecutivo...” op. cit., p. 1757].

${ }^{37}$ Por ejemplo, SENÉs apunta que, dada su excepcionalidad, la suspensión debería ser acordad únicamente "si de las actuaciones ejecutivas pudiera derivarse un perjuicio irreparable para el deudor" (énfasis añadido) [C. SENÉs MotilLA, "El Título Ejecutivo..." op. cit., p. 107]. Por su parte, GASCón INCHAUSTI apunta que la excepcionalidad derivara del momento en que se acuerde la suspensión, considerando que habría de adoptarse en supuestos en que la ejecución se encuentre en una fase avanzada, especialmente cuando hubieran comenzado las actividades propias de la expropiación forzosa. Ver: F. GASCÓN INCHAUSTI, El Título Ejecutivo Europeo... op. cit., pp. 194-195.
} 